\title{
Prototype Alat Pendeteksi Kebakaran Berbasis Internet Of Things Dengan Aktifasi Flame Sensor Menggunakan Arduino
}

\author{
Alridho Rizky Abrar ${ }^{1}$, Herman Mariadi Kaharmen'2, Iman Nur Hakim ${ }^{3}$ \\ Program Studi Teknik Keselamatan Otomotif, Politeknik Keselamatan Transportasi Jalan \\ E-mail: ridhorizky70@gmail.com
}

Received 14 September 2020; Reviewed 4 November 2020; Accepted 10 November 2020 Journal Homepage: http://ktj.pktj.ac.id/index.php/ktj

DOI: $10.46447 / \mathrm{ktj} . v 7 i 2.156$

\begin{abstract}
Abstrak
Kebakaran merupakan bencana yang dapat disebabkan oleh faktor manusia, faktor teknis maupun faktor alam yang tidak dapat diperkirakan kapan terjadinya. Internet of Things, atau dikenal juga dengan singkatan (IoT) merupakan sebuah konsep yang bertujuan untuk memperluas manfaat dari konektifitas internet yang tersambung secara terus-menerus. Dengan menggabungkan konsep Internet of Things kedalam suatu alat, akan mempermudah komunikasi sehingga lebih efektif. Metode penelitian yang digunakan merupakan jenis penelitian dan pengembangan atau Research and Development (R\&D). Penelitian Research and Development (R\&D) pada penelitian ini merupakan metode untuk menghasilkan dan menyempurnakan produk yang pernah diteliti sebelumnya yang hanya memakai satu sensor yaitu sensor asap. Pengujian responsifitas flame sensor dilakukan untuk mengetahui kinerja sensor, dilakukan 5 kali percobaan dengan titik yang berbeda dengan jarak $\pm 25 \mathrm{~cm}$, semakin besar api yang diuji maka tingkat ke sensitifitasan akan semakin meningkat. Responsifitas sensor untuk melakukan pendeteksian asap dengan jarak maksimal terhadap sumber asap dalam penelitian ini yaitu $25 \mathrm{~cm}$ membutuhkan waktu 10,2 detik ini menunjukkan penempatan sensor pada jarak $25 \mathrm{~cm}$ terhadap sumber masih aman. Semakin banyak dan tebal asap yang dihasilkan objek yang diuji maka jangkauan sensor MQ-2 akan semakin jauh, berarti prototype berjalan sesuai program yang telah di rancang.
\end{abstract}

Kata kunci: Kebakaran, IoT, Flame Sensor, Sensor MQ-2, SIM800L V2

\section{PENDAHULUAN}

Kebakaran merupakan bencana yang dapat disebabkan oleh faktor manusia, faktor teknis maupun faktor alam yang tidak dapat diperkirakan kapan terjadinya. Insiden kebakaran yang menimpa satu unit armada bus Transjakarta nomor lambung TJ452. Bus terbakar Senin malam sekitar pukul 20.30 WIB saat bus melintas melayani penumpang di Jalan Pos Pasar Baru Jakarta Pusat. Bus yang terbakar tersebut bermerek Hino dan menggunakan bahan bakar gas (CNG). Dalam peristiwa ini tidak ada korban jiwa, penumpang dan pengemudi berhasil keluar dengan selamat. Terkait dengan insiden ini, manajemen PT Transjakarta kemudian memutuskan menghentikan sementara pengoperasian 60 unit bus Hino berbahan bakar CNG, atau bus yang tipenya sama dengan bus yang terbakar tersebut (Bus-truck.id, 2019).

Mengetahui terjadi kebakaran merupakan hal yang sangat fatal bagi keselamatan jiwa manusia dan harta benda. Dengan menggabungkan konsep 
Internet of Things kedalam suatu alat, akan mempermudah komunikasi sehingga lebih efektif. Konsep monitoring hardware melalui jaringan internet ini yang biasa disebut dengan Internet of Things ( AK.Sharma, 2017).

Berdasarkan kasus diatas, perlu adanya suatu sistem yang mampu bekerja secara otomatis untuk mendeteksi adanya asap dan api sekaligus sistem peringatan yang diharapkan kebakaran dapat diketahui sedini mungkin dan disampaikan dengan cepat dan dapat di cegah sebelum membahayakan bagi keselamatan manusia. Pada penelitian ini akan dibuat rancang bangun prototype pendeteksi kebakaran dari faktor timbulnya api dan asap dengan peringatan melalui emergency call dan sms.

\section{ETODE PENELITIAN}

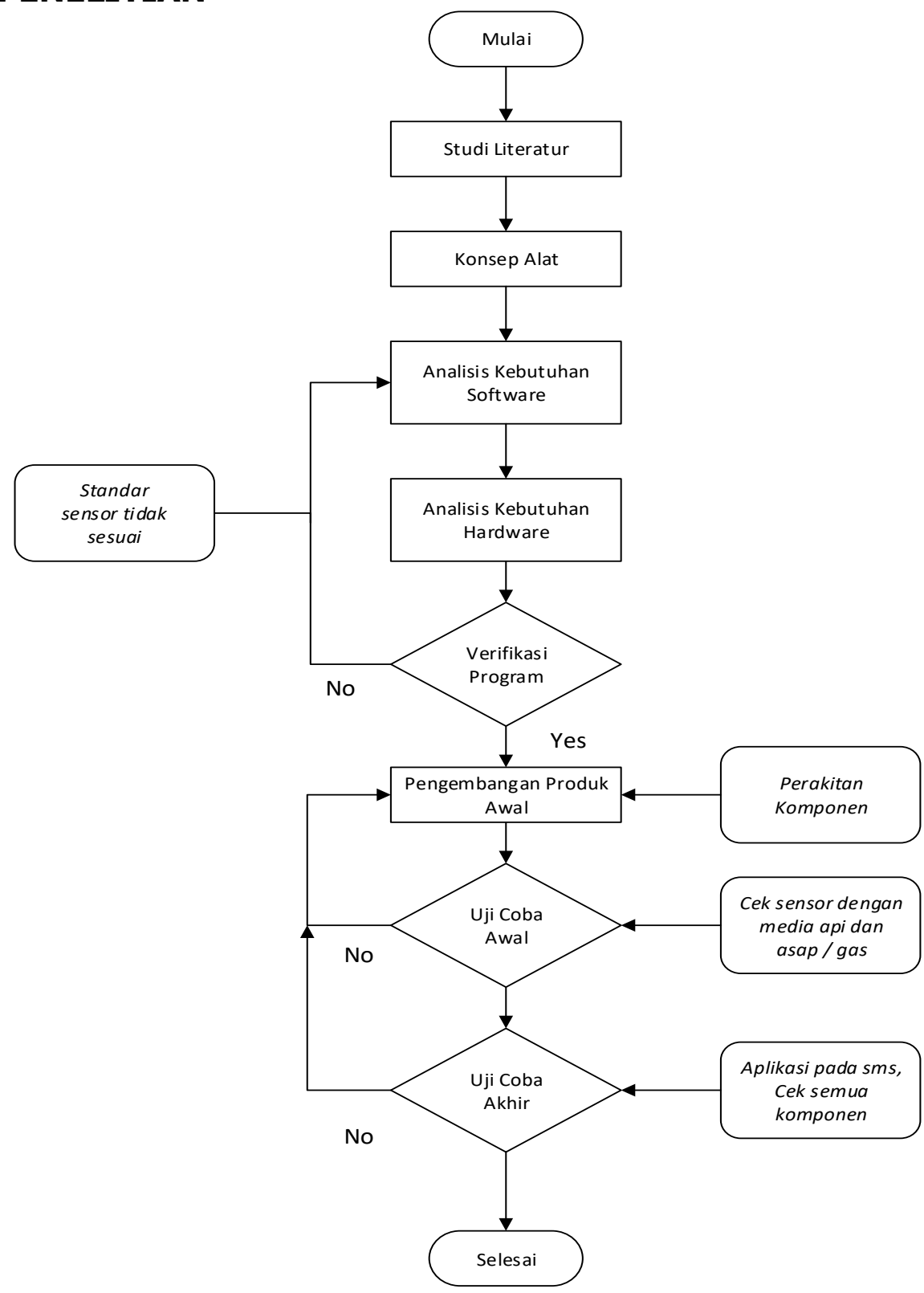

Gambar 1. Diagram Alur Penelitian 


\section{HASIL DAN PEMBAHASAN}

\section{A. Perakitan Prototype}

1. Wiring Diagram

Perancangan yang telah terkonsep akan dirancang pada Software Fritzing tahap perancangan adalah sebagai berikut:

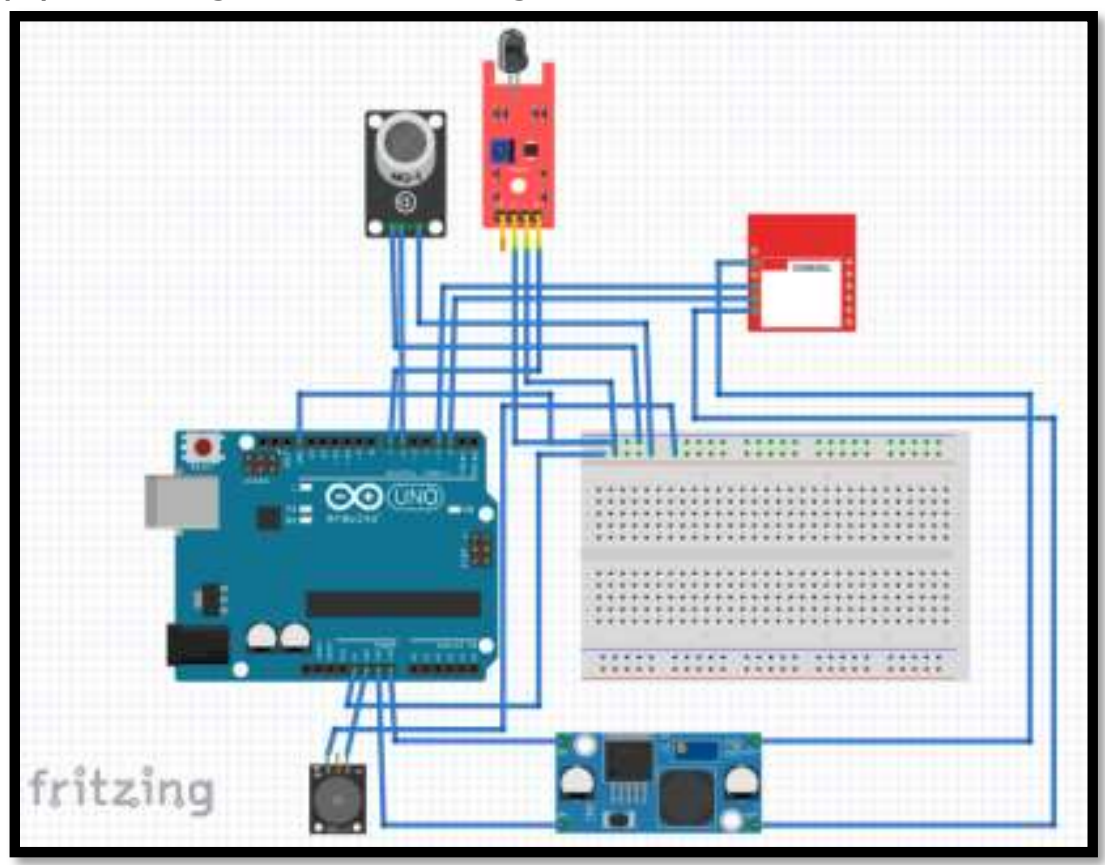

Gambar 2. Wiring Diagram

2. Perakitan Flame Sensor

Sebelum melakukan Pemasangan sensor harus memperhatikan langkahlangkah berikut:

a) Menentukan kode sensor

Setiap sensor mempunyai alamat sendiri-sendiri, oleh karena itu setiap sensor harus diberikan kode/nama yang berbeda.

b) Menentukan Kaki Sensor

Setiap Kaki sensor terdapat beberapa port yang mempunyai input berbeda, perlu diperhatikan agar pemasangan tidak terbalik.

c) Memastikan Pemasangan kaki sensor tepat pada port sensor

Setelah kode sensor dan kaki telah diketahui dengan pasti, maka pemasangan dapat dilaksanakan dengan tepat

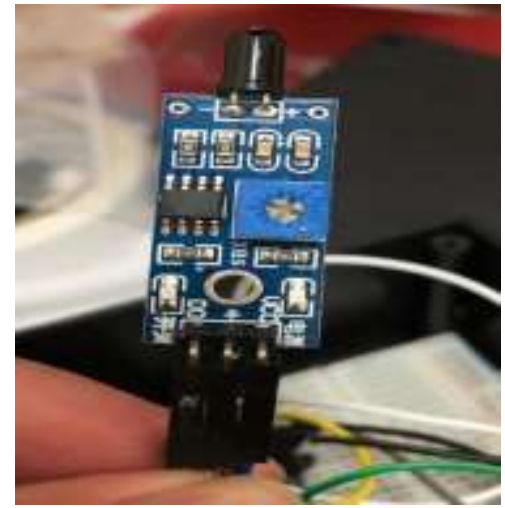

Gambar 3. Flame Sensor 
3. Perakitan Sensor MQ-2

Sama seperti flame sensor, sensor MQ-2 memiliki potensiometer yang harus diatur terlebih dahulu. Pemasangan sensor dilaksanakan dengan memperhatikan tahap - tahap sebagai berikut :

a) Menentukan Kaki Sensor Setiap Kaki sensor terdapat beberapa port yang mempunyai input berbeda, perlu diperhatikan agar pemasangan tidak terbalik.

b) Memastikan Pemasangan kaki sensor tepat pada port sensor setelah kode sensor dan kaki telah diketahui dengan pasti, maka pemasangan dapat dilaksanakan dengan tepat.

c) Memasang sensor MQ-2 ke box yang sudah di lubangi menggunakan lem bakar.

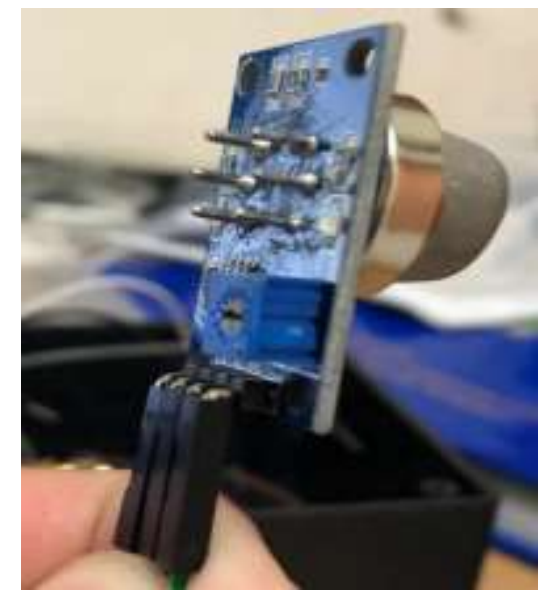

Gambar 4. Sensor MQ-2

4. Perakitan SIM800L V2

Sebelum pemasangan SIM 800L V2, perlu mengetahui spesifikasi dari Arduino Uno dan SIM 800L V2 dikarenakan perbedaan Operating Voltage yang mengakibatkan rusaknya komponen.

Dengan adanya perbedaan tersebut perlu adanya komponen tambahan untuk pengoperasian alat yaitu :

1. Adaptor power supply $9 \mathrm{~V}$

Dikarenakan spesifikasi SIM 800L V2 membutuhkan Voltage diatas 5V, sehingga membutuhkan daya tambahan dari adaptor power supply $9 \mathrm{~V}$ ke VIN Arduino Uno.

2. Regulator Switching

Pada VIN Arduino Uno memiliki daya sebesar 9V sehingga perlu adanya penurunan Voltage untuk memenuhi spesifikasi SIM 800L V2. Dengan adanya Regulator Switching berupa Adjustable Stepdown dengan seri LM2596S yang berfungsi menurunkan Voltage / Tegangan sesuai spesifikasi SIM 800L V2.

Adapun langkah pemasangan SIM 800L V2 dapat dilihat dari rangkaian gambar berikut:

a) Pemasangan Adaptor power supply 9V 


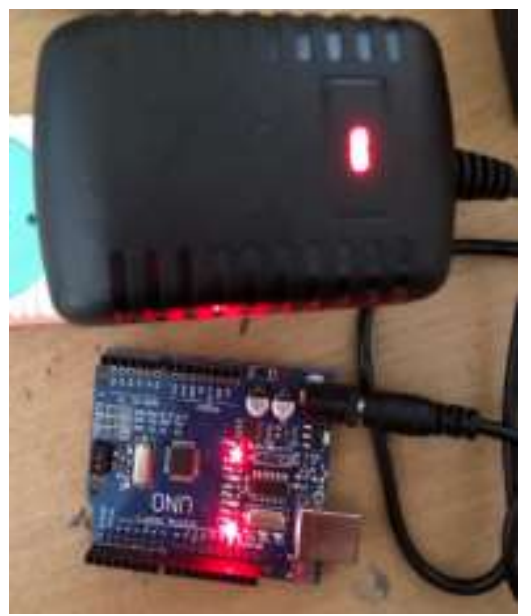

Gambar 5. Adaptor Power Supply 9V

b) Pemasangan Regulator Switching

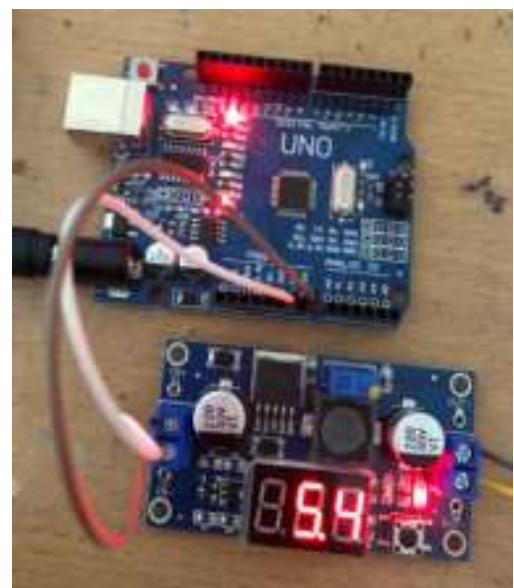

Gambar 6. Pemasangan Regulator Switching

c) Pemasangan SIM800L V2

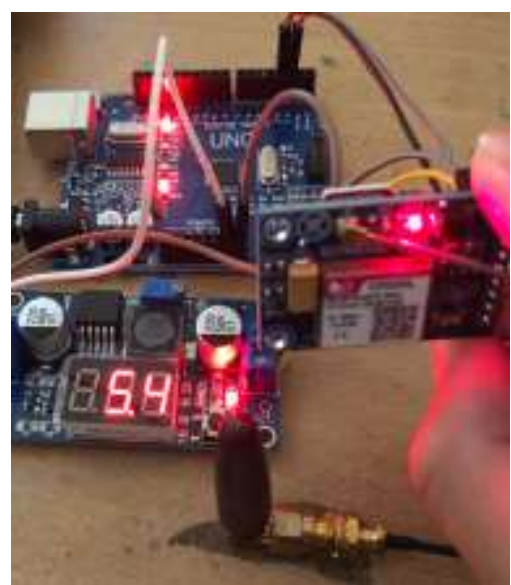

Gambar 7. SIM800L V2

5. Perakitan Buzzer

a) Menentukan kaki buzzer

b) Merakit buzzer di box 


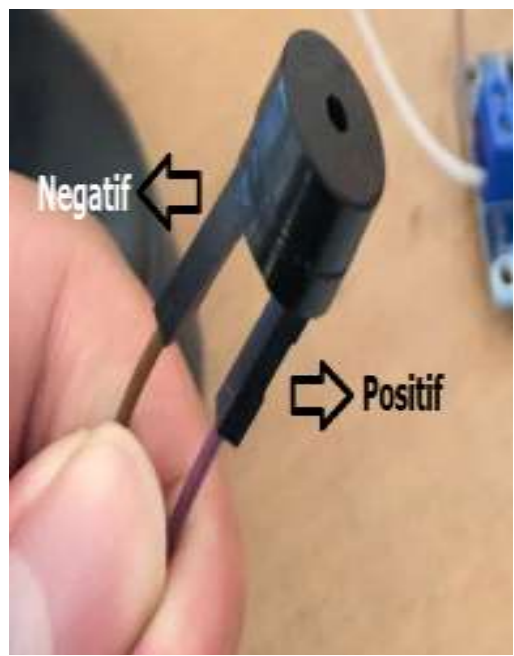

Gambar 8. Buzzer

\section{B. Uji Coba Awal}

\section{Uji coba flame sensor}

Untuk mengetahui kinerja sensor sesuai standar manual yang ada atau tidak maka dilakukan percobaan membandingkan flame sensor di alat dengan serial monitor yang sudah diprogram pada software Arduino IDE. Dalam percobaan ini penulis menggunakan korek api dengan pertimbangan api yang dikeluarkan sebagai indikator pembacaan flame sensor, sehingga hasil dari pembacaan sensor dapat digunakan sebagai data untuk perbandingan antara sensor dengan serial monitor. Hasil pengujian kondisi flame sensor dan pembacaan serial monitor pada tabel 1 dan 2 .

Tabel 1. Kondisi flame sensor

\begin{tabular}{|c|c|c|}
\hline Percobaan & Jarak $(\mathrm{cm})$ & Kondisi Flame Sensor \\
\hline Uji Coba 1 & 5 & On \\
\hline Uji Coba 2 & 10 & On \\
\hline Uji Coba 3 & 15 & On \\
\hline Uji Coba 4 & 20 & On \\
\hline Uji Coba 5 & 25 & On \\
\hline
\end{tabular}

Sumber : Hasil Pengujian, 2020

Tabel 2. Pembacaan serial monitor

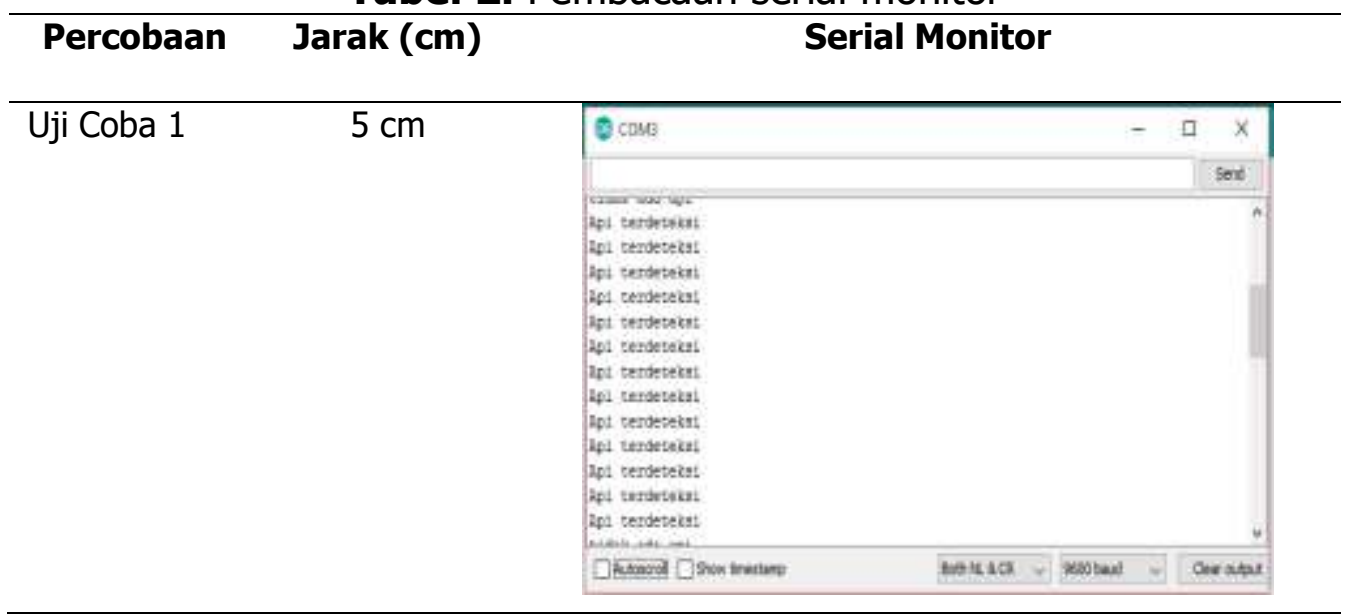




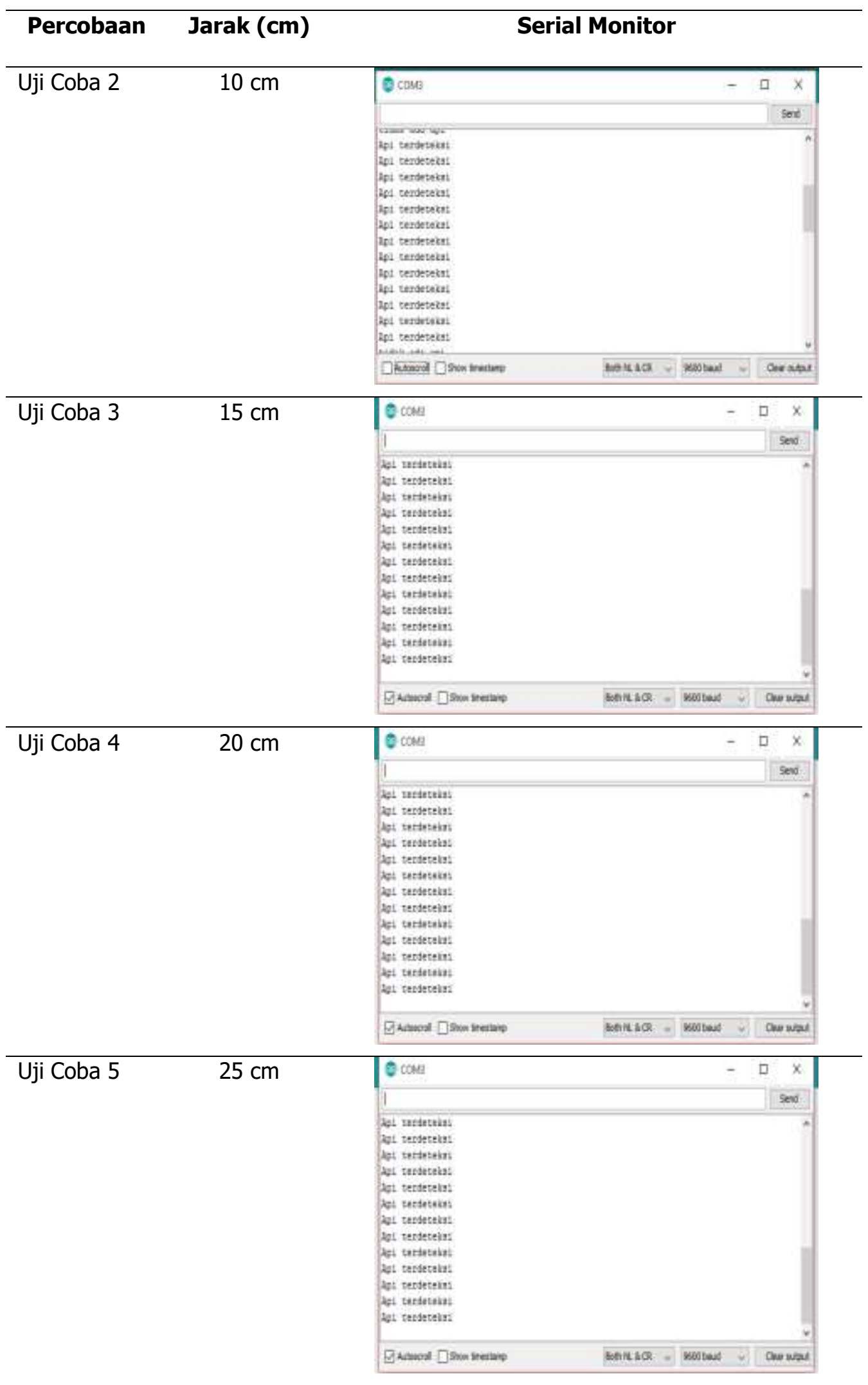

Sumber : Hasil Pengujian, 2020 


\section{Uji coba sensor MQ-2}

Uji coba sensor MQ-2 di lakukan untuk menunjukkan tingkat responsifitas sensor dengan cara memberikan asap di depan sensor atau pembacaan sensor yang di lakukan setelah adanya asap dengan hasil ditampilkan pada serial monitor Arduino IDE. Pengukuran dilakukan pada lima titik penempatan sensor dengan variasi jarak terhadap sumber asap. Hasil penelitian menunjukkan responsifitas sensor terhadap awal pembacaan.

Tabel 3. Waktu rata-rata awal pendeteksian sensor

\begin{tabular}{ccc}
\hline No. & $\begin{array}{c}\text { Jarak Penempatan } \\
\text { Sensor }\end{array}$ & $\begin{array}{c}\text { Waktu rata-rata awal } \\
\text { pendeteksian } \\
\text { (Total Waktu : 3) }\end{array}$ \\
\hline 1. & $5 \mathrm{~cm}$ & $1,7+1,4+1,1: 3=1,4$ detik \\
2. & $10 \mathrm{~cm}$ & $2,1+2,3+2,2: 3=2,2$ detik \\
3. & $15 \mathrm{~cm}$ & $3,5+3,4+3,7: 3=3,5$ detik \\
4. & $20 \mathrm{~cm}$ & $7,1+6,8+9,9: 3=7,9$ detik \\
5. & $25 \mathrm{~cm}$ & $11,2+9,0+10,4: 3=10,2$ detik \\
\hline
\end{tabular}

Sumber : Hasil Pengujian, 2020

Tabel di atas menunjukkan bahwa responsifitas sensor untuk melakukan pendeteksian asap dengan jarak maksimal terhadap sumber asap dalam penelitian ini yaitu $25 \mathrm{~cm}$ membutuhkan waktu 10,2 detik ini menunjukkan penempatan sensor pada jarak $25 \mathrm{~cm}$ terhadap sumber masih aman. Tergantung dari asap yang ditimbulkan semakin banyak dan tebal asap yang dihasilkan objek yang diuji maka jangkauan sensor MQ-2 akan semakin jauh.

\section{Uji coba SIM800L V2}

Untuk mengetahui output dari SIM800L V2 berjalan sesuai standar manual yang ada atau tidak maka dilakukan percobaan dengan mengaktifkan SIM800L V2 sesuai rancangan penulis. Apabila sensor berjalan sesuai standar manual maka akan ada notifikasi pada nomor handphone yang sudah di program pada Arduino IDE. Hasil penelitian menunjukkan responsifitas sensor terhadap awal pembacaan. Berikut tabel hasil pengujian responsifitas sensor pada tabel 4.

Tabel 4. Waktu operasional SIM800L V2

\begin{tabular}{lc}
\hline \multicolumn{1}{c}{ Percobaan } & Rata - rata \\
\hline Delay Pembacaan SIM 800L V2 & 7,8 detik \\
Delay Emergency Call SIM 800L V2 & 12,9 detik \\
Delay Pengiriman SMS SIM 800L V2 & 6,1 detik \\
Total & 26,8 detik \\
\hline
\end{tabular}

Sumber : Hasil Pengujian, 2020

Dari hasil uji coba pengukuran delay waktu yang dibutuhkan pada SIM800L V2 didapatkan waktu 26,8 detik. Tujuan pengukuran delay waktu agar dapat mempertimbangkan untuk pencegahan tanggap darurat apabila terjadi kebakaran sehingga dapat memperhitungkan waktu yang diperlukan dalam evakuasi. 


\section{Uji Coba Akhir}

1. Uji coba flame sensor

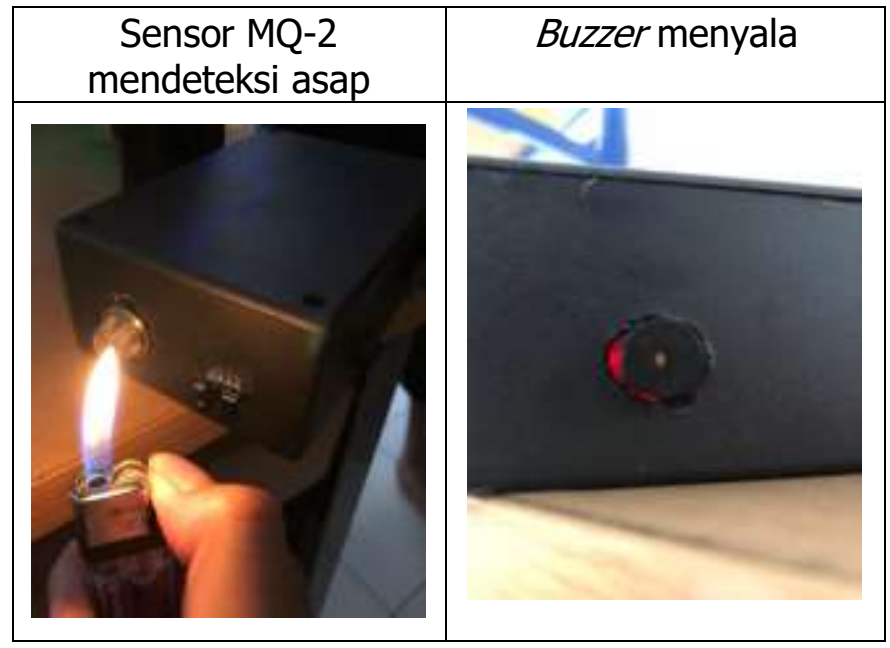

Gambar 9. Pendeteksian Api

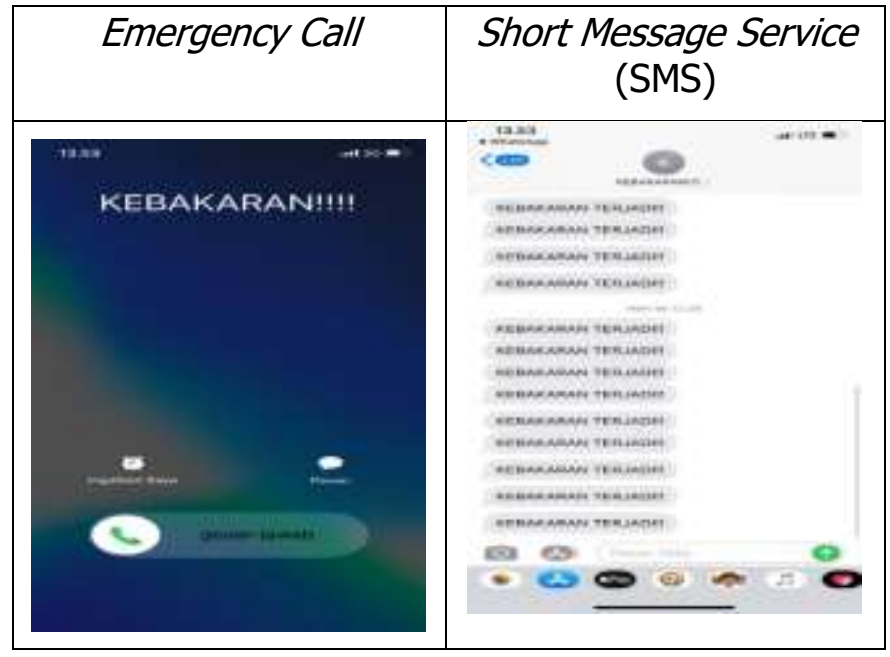

Gambar 10. Uji Coba Aktifasi Flame Sensor

2. Uji coba sensor MQ-2

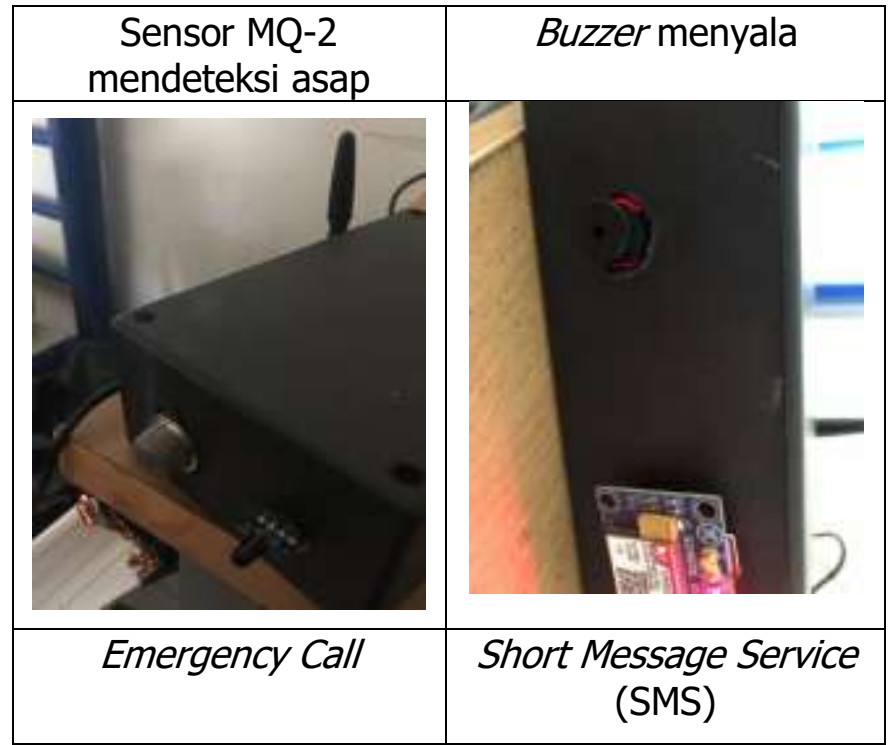




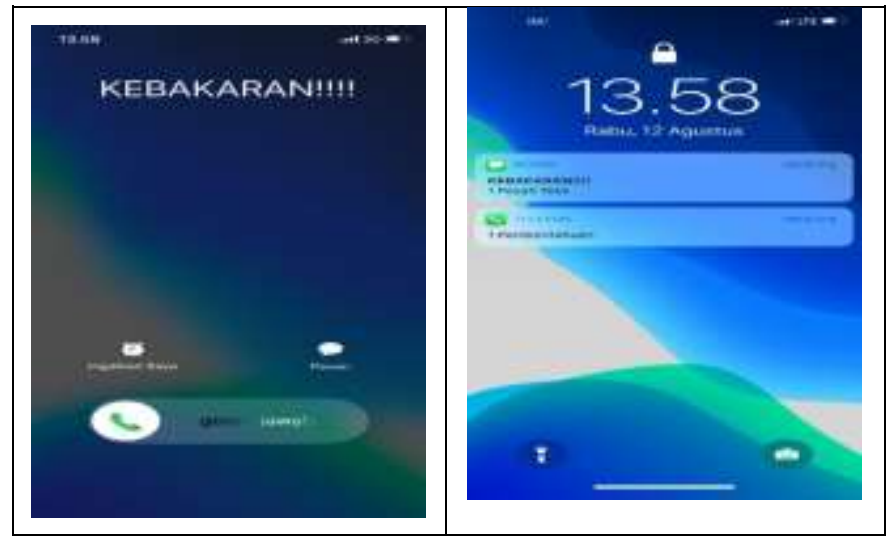

Gambar 11. Uji Coba Aktifasi Sensor MQ-2

Untuk lebih jelasnya lihat Tabel uji didapatkan dari hasil pengujian prototype alat pendeteksi kebakaran berbasis internet of things dengan aktifasi flame sensor dan sms gateway menggunakan arduino, yang di rakit pada sebuah box Berikut adalah tabel hasil pengujian prototype alat :

Tabel 5. Tabel Uji Prototype

\begin{tabular}{|c|c|c|c|c|c|}
\hline \multirow[b]{2}{*}{ No } & \multicolumn{4}{|c|}{ Kondisi Sensor } & \multirow[b]{2}{*}{ Keterangan } \\
\hline & Sensor MQ-2 & Flame Sensor & GSM Shield & Buzzer & \\
\hline 1 & OFF & OFF & OFF & OFF & $X$ \\
\hline 2 & ON & OFF & ON & ON & $\checkmark$ \\
\hline 3 & ON & ON & ON & ON & $\checkmark$ \\
\hline 5 & OFF & ON & ON & ON & $\checkmark$ \\
\hline
\end{tabular}

Sumber : Hasil Pengujian, 2020

Keterangan :

$\checkmark$ = Ada Kebakaran

Tanda peringatan aktif (Buzzer), Salah satu ataupun semua sensor mendeteksi (MQ-2 dan Flame sensor, SIM800L V2 melakukan emergency call dan pemberitahuan berupa Short Message Service (SMS)

$\mathrm{X}=$ Tidak ada Kebakaran

Tanda peringatan tidak aktif (Buzzer), Salah satu ataupun semua sensor tidak mendeteksi (MQ-2 dan Flame sensor, SIM800L V2 tidak melakukan emergency call dan pemberitahuan berupa Short Message Service (SMS)

\section{SIMPULAN}

Berdasarkan uraian perancangan, pembuatan dan pembahasan tentang prototype alat pendeteksi kebakaran berbasis internet of things dengan aktifasi flame sensor dan sms gateway menggunakan arduino dapat disimpulkan: (a) Rancang bangun prototype alat pendeteksi kebakaran berbasis internet of things dengan aktifasi flame sensor dan sms gateway menggunakan arduino dapat terealisasi menjadi sebuah alat yang dapat diaplikasikan dan disimulasikan serta dapat melakukan emergency call ; (b) Cara kerja prototype dapat diperoleh dengan pembacaan flame sensor, sensor MQ-2, serta berfungsinya buzzer (alarm), SIM800L V2 aktif untuk melakukan panggilan berupa miscall dan menampilkan data berupa tulisan "Kebakaran Terjadi!" pada Short Message 
Service (SMS) di handphone, Komponen ini dijadikan sebagai komponen pemberitahuan secara realtime kepada pengguna kendaraan; (c) Pengujian responsifitas flame sensor dan sensor MQ-2 dilakukan untuk mengetahui kinerja sensor terhadap sumber masih aman. Tergantung dari objek yang ditimbulkan, semakin besar intensitas objek yang diuji maka tingkat responsifitas flame sensor dan sensor MQ-2 akan semakin meningkat. Berarti sensor MQ-2 dan Flame sensor yang di alat memiliki kepekaan yang cukup bagus dikarena cepat mendeteksi suatu kebakaran; (d) Kelemahan dari alat ini terdapat pada SIM800L V2 yang memiliki tegangan tidak stabil pada saat pencarian dan tergantung dari lokasi terdapat sinyal atau tidak dari sim card yang digunakan.

\section{SARAN}

Dalam penelitian ini masih terdapat beberapa hal yang dapat ditingkatkan dengan menambah sensor suhu agar lebih signifikan, menambah IC regulator agar tegangan pada rangkaian tetap stabil.

\section{DAFTAR PUSTAKA}

Andrianto, H. (2015). Pemprograman Mikrokontroller AVR ATmega16 Menggunakan Bahasa C (Code vision AVR) Revisi Kedua. Bandung: Informatika Bandung. Arfian, R. (2017). Rancang Bangun Perangkat Pendeteksi Asap Rokok Dengan Kombinasi Sensor Gas MQ 2 dan TGS 2600. JCONES Vol. 6.

Awl, H. N. (2018). Smart Home System Based on GSM Network. Kurdistan Journal of Applied Research (KJAR).

Djuandi, F. (2011). Pengenalan Arduino.

Kamelia, L. (2019). Fire Disaster Early Detection System in Residential Areas. 4th Annual Applied Science and Engineering Conference.

Kendall, B. (2013). Make Use of Getting Started with Arduino a Beginners Guide.

Mobin, M. I. (2016). An Intelligent Fire Detection and Mitigation System Safe from Fire (SFF). International Journal of Computer Applications.

Mulyati, S. (2018). Internet of Things (IOT) Pada Prototipe Pendeteksi Kebocoran Gas Berbasi MQ-2 dan SIM800L.

Putra, B. (2015). Rancang Bangun Sistem Otomasi Pintu Emergency Pada Prototipe Miniataur Bus Ketika Terjadi Kebakaran.

Rifai, A. F. (2016). Sistem Pendeteksi dan Monitoring Kebocoran Gas (Liquefied Petrolum Gas) Berbasi Internet of Things.

S, Y. (2016). Home Based Fire Monitoring and Warning System.

Smith, A. G. (2011). Introduction to Arduino: A piece of cake.

Sofyan. (2019). Rancang Bangun Sistem Pendeteksian Kebakaran Ruangan Menggunakan Mikrokontroller Arduino Berbasis Internet of Things.

Syam, R. (2013). Dasar-dasar Teknik Sensor untuk Beberapa Kasus Sederhana. Universitas Hasanudin: Teknik Mesin, Hal-13, 41 dan 54.

Wicaksono, F. (2019). Aplikasi Arduino dan Sensor. Bandung: Informatika.

Yahmianto, B. (2015). Rancang Bangun Pendeteksi Karbon Monoksida Dengan Aktifasi Power Window dan Lampu Hazard Berbasis Arduino. 